Erratum

\title{
Erratum to "Modeling of Hydrophysical Properties of the Soil as Capillary-Porous Media and Improvement of Mualem-Van Genuchten Method as a Part of Foundation Arrangement Research"
}

\author{
Vitaly Terleev, ${ }^{1}$ Aleksandr Nikonorov, ${ }^{1}$ Vladimir Badenko, ${ }^{1}$ Inna Guseva, ${ }^{1}$ Yulia Volkova, \\ Olga Skvortsova, ${ }^{1}$ Sergey Pavlov, ${ }^{1}$ and Wilfried Mirschel ${ }^{2}$ \\ ${ }^{1}$ Peter the Great St. Petersburg Polytechnic University, Polytechnicheskaya 29, Saint Petersburg 195251, Russia \\ ${ }^{2}$ Leibniz-Centre for Agricultural Landscape Research, Eberswalder Straße 84, 15374 Müncheberg, Germany \\ Correspondence should be addressed to Aleksandr Nikonorov; coolhabit@yandex.ru \\ Received 9 August 2016; Accepted 24 August 2016 \\ Copyright ( 2016 Vitaly Terleev et al. This is an open access article distributed under the Creative Commons Attribution License, \\ which permits unrestricted use, distribution, and reproduction in any medium, provided the original work is properly cited.
}

In the article titled "Modeling of Hydrophysical Properties of the Soil as Capillary-Porous Media and Improvement of Mualem-Van Genuchten Method as a Part of Foundation Arrangement Research" [1], there was an error in reference [22], which should be corrected as follows:

[22] R. A. Poluektov and V. V. Terleev, "Crop simulation model of the second and the third productivity levels," in Modelling Water and Nutrient Dynamics in Soil-Crop Systems, pp. 75-89, Springer, Dordrecht, The Netherlands, 2007.

\section{References}

[1] V. Terleev, A. Nikonorov, V. Badenko et al., "Modeling of hydrophysical properties of the soil as capillary-porous media and improvement of mualem-van genuchten method as a part of foundation arrangement research," Advances in Civil Engineering, vol. 2016, Article ID 8176728, 7 pages, 2016. 


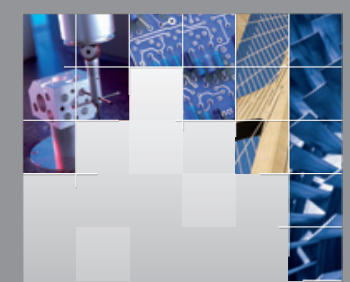

\section{Enfincering}
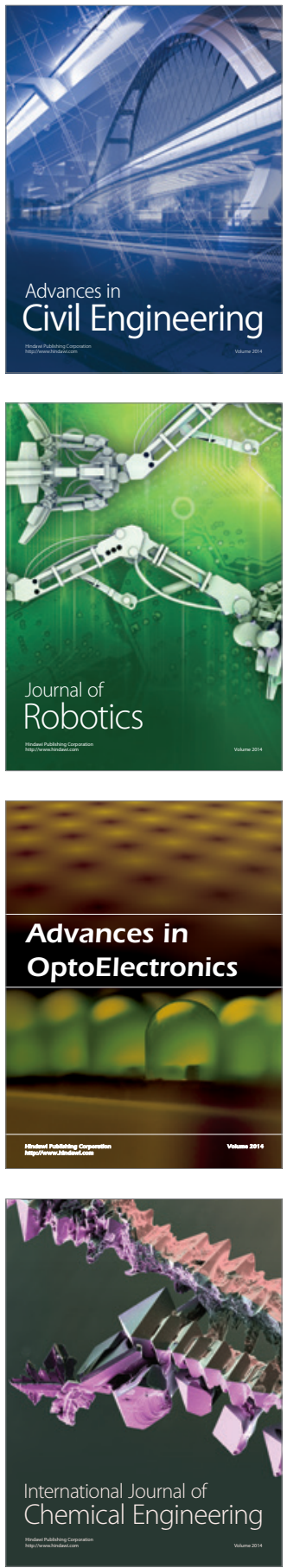

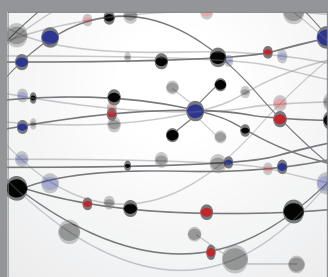

The Scientific World Journal

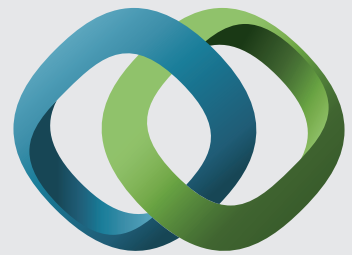

\section{Hindawi}

Submit your manuscripts at

http://www.hindawi.com
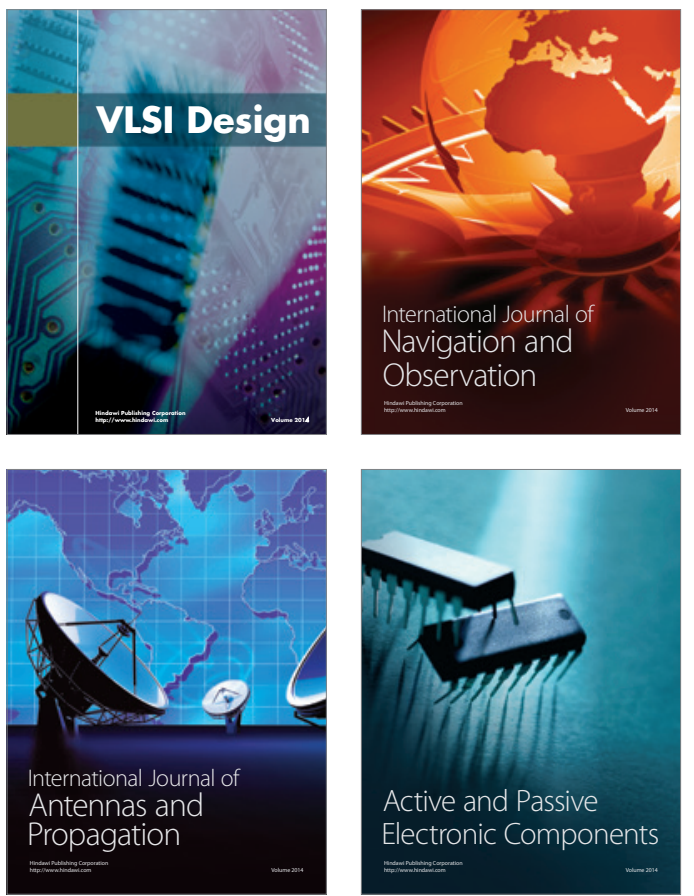
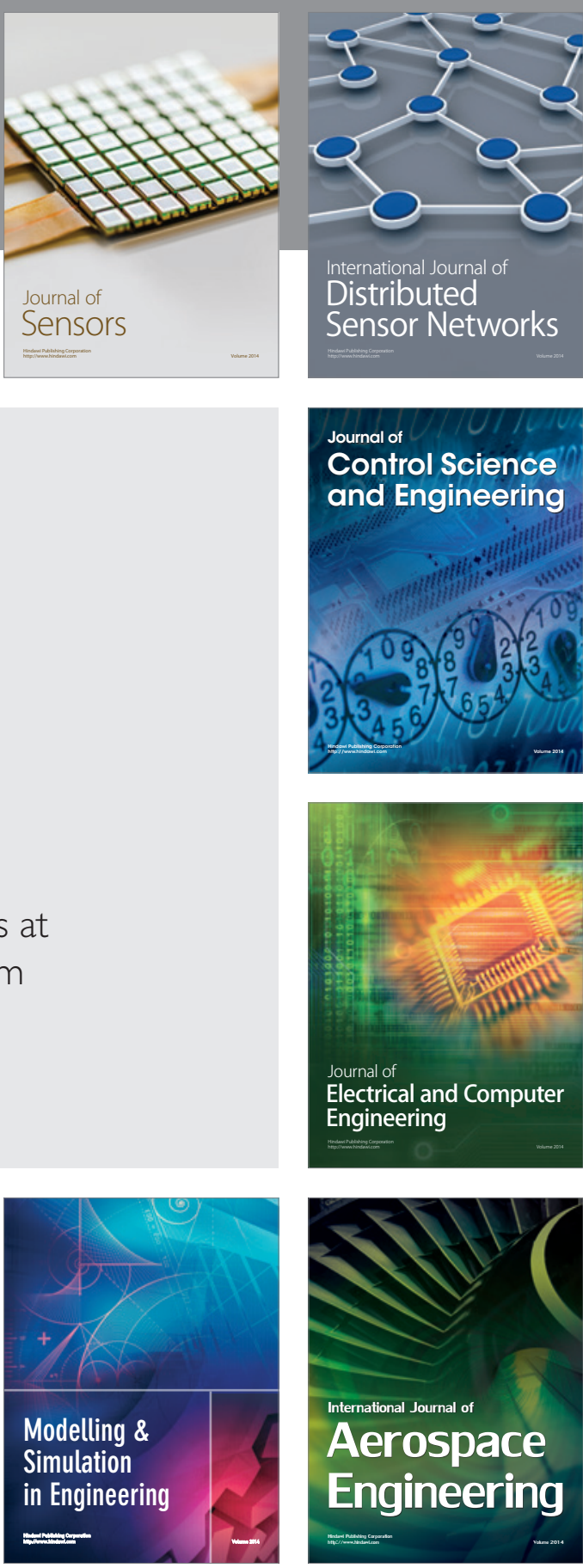

International Journal of

Distributed

Sensor Networks

Journal of

Control Science

and Engineering
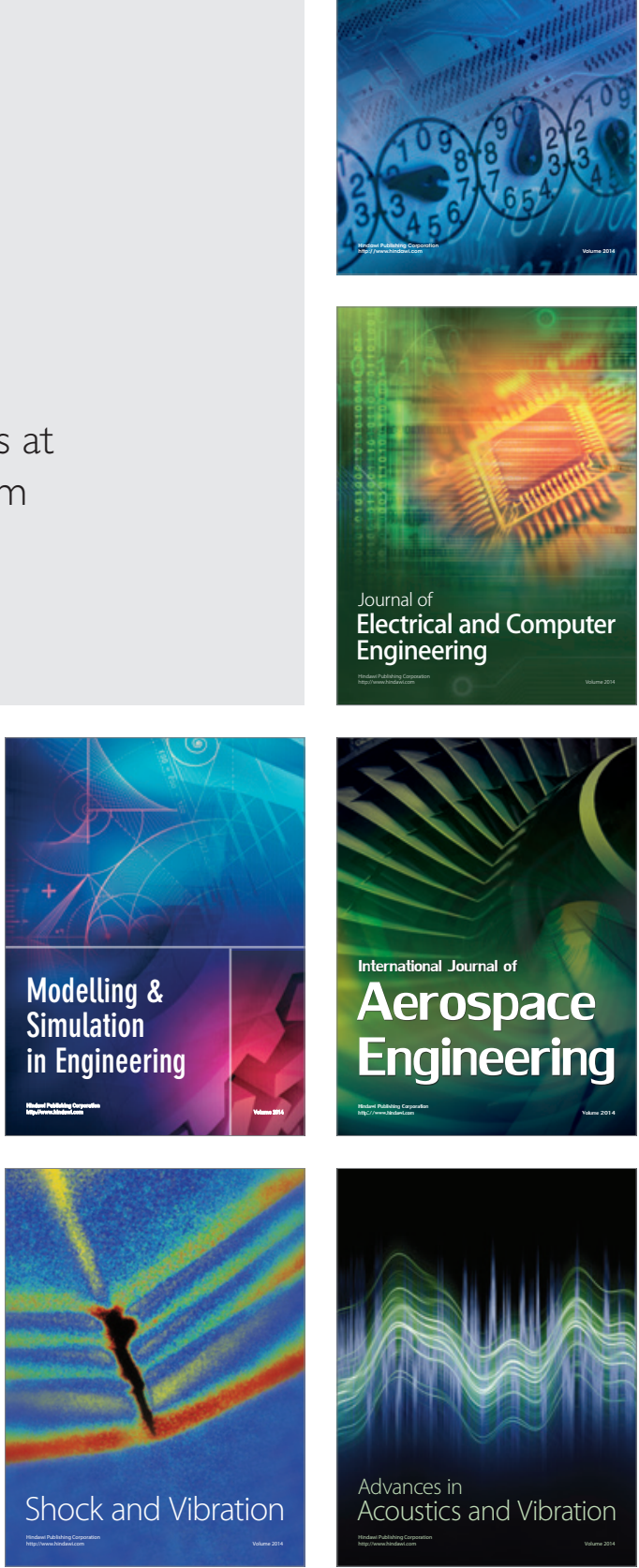